\title{
Cuidados de enfermagem ao paciente pós-parada cardiorrespiratória: Uma revisão integrativa
}

\author{
Nursing care for patient after cardiorespiratory arrest: An integrative review \\ Atención de enfermería del paciente post-cardiorrespirator: Una revisión integrativa
}

Recebido: 13/03/2021 | Revisado: 20/03/2021 | Aceito: 24/03/2021 | Publicado: 01/04/2021

Eric Rosa Pereira

ORCID: https://orcid.org/0000-0003-0202-6653 Centro Universitário UNIABEU, Brasil E-mail: ericrosap@yahoo.com.br

Viviane de Melo Souza

ORCID: https://orcid.org/0000-0001-7823-7356 Centro Universitário UNIABEU, Brasil E-mail: enfvivianemelo@gmail.com

Priscilla Valladares Broca

ORCID: https://orcid.org/0000-0003-3392-910X

Escola de Enfermagem Anna Nery, Brasil

E-mail: priscillabroca@gmail.com

Maria Elisangela da Silva

ORCID: https://orcid.org/0000-0002-1181-7222 Centro Universitário UNIABEU, Brasil E-mail: elielisangelajesus@gmail.com

Thais Carolina Joviano da Silva

ORCID: https://orcid.org/0000-0002-6239-8056 Centro Universitário UNIABEU, Brasil E-mail: thaiscarolina31@ hotmail.com

Fábio José de Almeida Guilherme ORCID: https://orcid.org/0000-0001-6484-2870 Força Aérea Brasileira, Brasil Instituto de Medicina Aeroespacial, Brasil

E-mail: fabioguilherme1@yahoo.com.br

Renata da Silva Hanzelmann

ORCID: https://orcid.org/0000-0003-4129-0481 Centro Universitário São José, Brasil E-mail: profa.hanzelmann@gmail.com

Ronilson Gonçalves Rocha

ORCID: https://orcid.org/ 0000-0003-4097-8786

Universidade do Estado do Rio de Janeiro, Brasil

E-mail: ronilson.uerj@gmail.com

\begin{abstract}
Resumo
Objetivos: identificar os cuidados de enfermagem após a reanimação da PCR; produzir um quadro de síntese sobre os principais cuidados de enfermagem. Metodologia: trata-se de uma revisão integrativa da literatura realizada nas bases de dados LILASCS, MEDLINE e BDENF. O recorte temporal envolveu os artigos publicados nos últimos cinco anos. Como critério de inclusão teve-se: artigos que tratam da temática parada cardiorrespiratória nos serviços de emergência, centro de terapia intensiva e unidade semi intensiva. Como critério de exclusão deu-se os artigos que abordam a parada cardiorrespiratória no ambiente pré-hospitalar móvel. Resultados: o cuidado com a hipotermia preventiva, o registro dos cuidados prestados, controle rigoroso dos sinais vitais e a avaliação do distúrbio metabólico configuram-se como cuidados fundamentais prestados pelos enfermeiros. O quadro informativo caracterizou os cuidados de enfermagem frente ao paciente em parada cardiorrespiratória, como fonte de consulta. Conclusão: os cuidados fundamentais de enfermagem ao paciente em parada cardiorrespiratória foram expostos nesta pesquisa. $\mathrm{O}$ quadro informativo configura-se como fonte de consulta que irá nortear os cuidados de enfermagem ao paciente pós parada cardiorrespiratória.
\end{abstract}

Palavras-chave: Parada cardiorrespiratória; Cuidados; Enfermagem.

\section{Abstract}

Objectives: to identify nursing care after CPR resuscitation; produce a summary table of the main nursing care. Methodology: this is an integrative literature review carried out in the LILASCS, MEDLINE and BDENF databases. The time frame was the articles published in the last five years. The inclusion criteria were: articles dealing with the 
theme of cardiorespiratory arrest in emergency services, intensive care unit and semi-intensive care unit. Exclusion criteria were articles that address cardiorespiratory arrest in the mobile prehospital environment. Results: the care with preventive hypothermia, the record of care provided, strict control of vital signs and the assessment of metabolic disorder are configured as fundamental care provided by nurses. The information board characterized nursing care for patients in cardiorespiratory arrest, as a source of consultation. Conclusion: basic nursing care for patients in cardiac arrest were exposed in this research. The information board is configured as a source of consultation that will guide nursing care for patients after cardiac arrest.

Keywords: Cardiorespiratory arrest; Care; Nursing.

\section{Resumen}

Objetivos: identificar los cuidados de enfermería después de la reanimación con RCP; Elaborar un cuadro resumen de los principales cuidados de enfermería. Metodología: se trata de una revisión integradora de la literatura realizada en las bases de datos LILASCS, MEDLINE y BDENF. El marco temporal fueron los artículos publicados en los últimos cinco años. Los criterios de inclusión fueron: artículos sobre el tema de parada cardiorrespiratoria en servicios de urgencias, unidad de cuidados intensivos y unidad de cuidados semi-intensivos. Los criterios de exclusión fueron los artículos que abordan la parada cardiorrespiratoria en el entorno prehospitalario móvil. Resultados: la atención con hipotermia preventiva, el registro de la atención brindada, el control estricto de los signos vitales y la evaluación del trastorno metabólico se configuran como cuidados fundamentales brindados por enfermeras. El panel informativo caracterizó la atención de enfermería al paciente en parada cardiorrespiratoria, como fuente de consulta. Conclusion: en esta investigación se expusieron los cuidados básicos de enfermería para pacientes en paro cardíaco. El panel de información se configura como una fuente de consulta que orientará la atención de enfermería a los pacientes después de un paro cardíaco.

Palabras clave: Paro cardiorrespiratorio; Cuidado; Enfermería.

\section{Introdução}

A parada cardiorrespiratória (PCR) caracteriza-se pela cessação súbita da circulação sistêmica, associada à ausência da atividade respiratória e gera grandes complicações. Contudo, pode ser reversível em situações em que o atendimento seja imediato. Assim sendo, considerada umas das principais emergências que acarretam prejuízos a vida humana, necessitando de uma equipe de saúde hábil na prestação da assistência pertinente, tanto em ambiente extra ou intra-hospitalar (Cruz, Rêgo, \& Lima, 2019).

A padronização da assistência com a criação de protocolos e algoritmos internacionais, permite identificação prévia e intervenção para cada episódio com foco nos cuidados após o retorno da circulação, e como resultado, um melhor prognóstico desse paciente que sofreu uma parada cardiorrespiratória, considerada uma das emergências cardiovasculares com alta morbidade e mortalidade (Bernoche et al., 2019).

Sabe-se que, os dados no Brasil referentes à incidência de casos de PCR são bem reduzidos, estima-se que ocorra aproximadamente 200 mil por ano, sendo 50\%, em ambiente hospitalar. Cerca de $80 \%$ dos casos de PCR em ambiente extra hospitalar e são causados por, fibrilação ventricular (FV) e taquicardia ventricular sem pulso (TVSP), tendo êxito na reversão quando se tem um tratamento de 3 a 5 minutos do início da PCR, com uma taxa de sobrevida de 50\% a 70\%. Por outro lado, quando a PCR ocorre no ambiente hospitalar o ritmo com maior frequência é a atividade elétrica sem pulso (AESP) ou assistolia, com taxas de sobrevida abaixo de 17\% (Bernoche et al.,2019).

A reanimação da parada cardiorrespiratória deve ser feita com o uso de compressões torácicas a uma frequência de 100 a 120 compressões/minutos, comprimindo o tórax a uma profundidade de 2 polegadas $(5 \mathrm{~cm})$ para adulto médio, evitando ultrapassar a profundidade de 2,4 polegadas $(6 \mathrm{~cm})$, permitindo o retorno total do tórax após cada compressão, minimizando as interrupções, ventilando adequadamente (30 compressões para cada 2 ventilações) (American Heart Association [AHA], 2015).

Quando se tem sucesso na reversão da PCR, está diretamente ligado a presença de uma pessoa no momento exato do ocorrido para que se inicie o mais rápido possível as manobras de reanimação. Dessa maneira, o profissional de saúde não deve ultrapassar mais de 10 segundos para fazer a verificação do pulso do paciente e assim iniciar a manobra (AHA, 2015). 
Nesse contexto, o enfermeiro possui muitas responsabilidades, ele será o primeiro a identificar a PCR e iniciar o suporte básico de vida (SBV) com auxílio de sua equipe até a chegada de outros profissionais. Cabe a ele a organização do carrinho de parada, com as medicações necessárias, equipamentos e insumos de forma sistematizada (Carvalho, Santos, \& Viana, 2015).

Compreende-se que a organização no momento do atendimento é de grande importância, dessa forma, é necessário que haja uma padronização própria por parte da equipe de enfermagem que deve estar muito bem treinada e liderada pelo enfermeiro, visto que é dever desses profissionais zelar pelo seu ambiente de trabalho (Castanheira et al., 2020).

O Atendimento do paciente após o retorno da circulação espontânea (RCE) requer muita atenção à oxigenação, controle da pressão arterial, avaliação da intervenção coronária percutânea, controle direcionado de temperatura e neuroproteção multimodal (AHA, 2020).

Neste contexto, os cuidados de enfermagem realizados após a reanimação do paciente são imprescindíveis. A sistematização da assistência de enfermagem (SAE) é uma função restrita ao enfermeiro e conduz as práticas de toda a equipe de enfermagem, dessa maneira organizando a execução do processo de enfermagem e contribuindo nas decisões dos enfermeiros (Costa, Santos, \& Silva, 2014).

O uso do processo de enfermagem ao paciente pós reanimação da PCR, faz-se necessário como parte de uma elaboração do plano de cuidado que atenda às suas necessidades, priorizando as respostas no processo saúde doença, com base no conhecimento cientifico utilizando as taxonomias: Associação Norte-Americana de Diagnósticos de Enfermagem (NANDA), Classificação das Intervenções de Enfermagem (NIC) e Classificação dos Resultados de Enfermagem (NOC), com ênfase no equilíbrio hemodinâmico para o seu quadro clínico (Alves, Chaves, Freitas, \& Monteiro, 2007).

Desse modo, surge como objeto do estudo a atuação da enfermagem nos cuidados após a reanimação da PCR e tem como objetivos: Identificar os cuidados de enfermagem após a reanimação da PCR; Produzir uma tabela de síntese sobre os principais cuidados.

\section{Metodologia}

Essa pesquisa trata-se de uma revisão integrativa da literatura, usando como critério a coleta de dados, análise e apresentação dos resultados. Desse modo, foram aplicadas as seguintes etapas para a construção da revisão integrativa da literatura: 1- seleção da pergunta de pesquisa; 2- definição dos critérios de inclusão e exclusão de estudos e seleção da amostra; 3- definição das informações a serem extraídas dos estudos selecionados; 4- avaliação dos estudos incluídos na revisão; 5interpretações dos resultados e 6- apresentação da revisão (Mendes, Silveira, \& Galvão, 2008).

Usando como questão norteadora: Quais são os cuidados de enfermagem após a reanimação da PCR? Realizou-se uma busca na Biblioteca Virtual em Saúde (BVS), por meio das bases de dados da Literatura Relativa às Ciências da Saúde (LILACS), Literatura Internacional da Área Médica e Biomédica (MEDLINE) e Bibliografia Especializada na Área de Enfermagem (BDENF). Utilizando como critérios de inclusão os artigos em português, no período de 2015 a 2019 e disponíveis na integra. Como critérios de exclusão foram utilizados os artigos repetidos e artigos fora da temática.

Aplicando-se como descritores de assunto, segundo os Descritores em Ciência de Saúde (DECS), os termos em português: Parada cardiorrespiratória, Cuidados e Enfermagem. Os descritores foram associados através do operador booleano “AND”. A pesquisa dos artigos ocorreu no mês de abril de 2020, conforme observada na Tabela 1. 
Tabela 1. Lista dos estudos encontrados pela associação dos descritores da pesquisa.

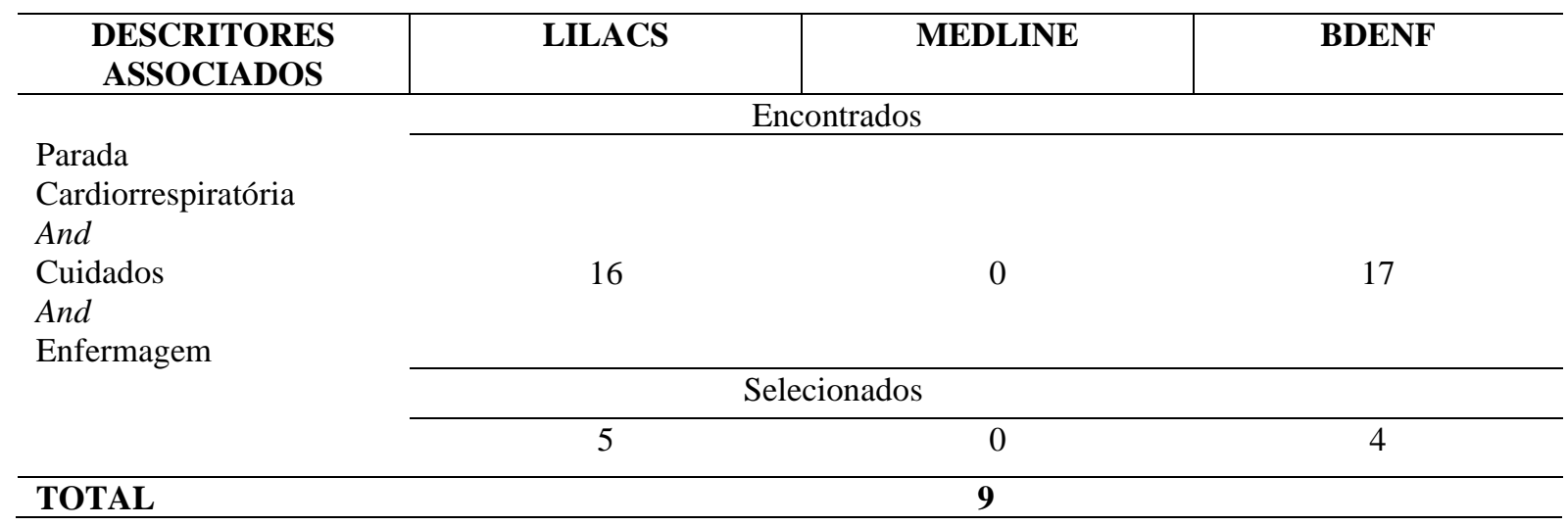

Fonte: Banco de Dados da LILACS, MEDLINE e BDENF (2020).

Observa-se que a base BDENF foi a que mais apresentou artigos totalizando 17, seguida pela LILACS com 16 e MEDLINE com nenhuma publicação. Porém, a maioria dos artigos utilizados na pesquisa foi encontrado na LILACS.

A Tabela 2, conforme descrita abaixo, apresenta a análise dos artigos em relação ao ano de publicação, revista de publicação, tipo de estudo e país de publicação.

Tabela 2. Análise dos artigos.

\begin{tabular}{|c|c|c|}
\hline & $\mathbf{F}$ & $\mathbf{F} \%$ \\
\hline \multicolumn{3}{|l|}{ Ano de Publicação do periódico } \\
\hline 2015 & 2 & 22,22 \\
\hline 2016 & 1 & 11,11 \\
\hline 2017 & 3 & 33,33 \\
\hline 2018 & 2 & 22,22 \\
\hline 2019 & 1 & 11,11 \\
\hline \multicolumn{3}{|l|}{ Revistas de Publicações } \\
\hline Revista pesq. cuid. fund. online -UNIRIO & 2 & 22,22 \\
\hline Revista escola enfermagem- USP & 1 & 11,11 \\
\hline Tese (MPEA-tese e dissertação) & 1 & 11,11 \\
\hline Ciência medicina (Campinas) & 1 & 11,11 \\
\hline Revista eletrônica enfermagem & 1 & 11,11 \\
\hline Revista enfermagem UFPE- online & 2 & 22,22 \\
\hline Cuidados arte enfermagem & 1 & 11,11 \\
\hline \multicolumn{3}{|l|}{ Tipos de pesquisa } \\
\hline Quantitativa & 9 & 100 \\
\hline \multicolumn{3}{|l|}{ Tipos de estudo } \\
\hline Revisão integrativa & 3 & 33,33 \\
\hline Pesquisa de campo & 6 & 66,66 \\
\hline \multicolumn{3}{|l|}{ País } \\
\hline Brasil & 9 & 100 \\
\hline Total & 9 & $100 \%$ \\
\hline
\end{tabular}


No ano de 2017 foi o ano que teve o maior índice de artigos publicados, totalizando 3 artigos. Já nos anos de 2015 e 2018 foram publicados 2 artigos cada. E nos anos de 2016 e 2019 foram encontrados apenas 1 publicação.

Dentre os artigos selecionados as revistas que mais publicaram artigos foi a Revista enfermagem UFPE-online e Revista pesq. cuid. fund. Online - UNIRIO com 2 artigos cada. Na maior parte das publicações a predominância dos tipos de pesquisas são quantitativas com 9 artigos. No que se refere aos tipos de estudos, dentro do que foi encontrado, identifica-se que a maioria é pesquisa de campo com 6 artigos e 3 são revisão integrativa.

Todas as publicações que foram selecionadas são brasileiras com idioma em português, seguindo um dos critérios de inclusão da pesquisa. Posteriormente ao término da pesquisa foram selecionados 9 artigos, e realizado uma leitura crítica e a análise dos mesmo que foram utilizados para a próxima fase do trabalho que é a discussão.

O Fluxograma 1 detalha os artigos encontrados e selecionados na base de dados, com critério de inclusão e exclusão dos encontrados fora da temática.

Fluxograma 1. Fluxograma com o passo a passo da coleta dos artigos.

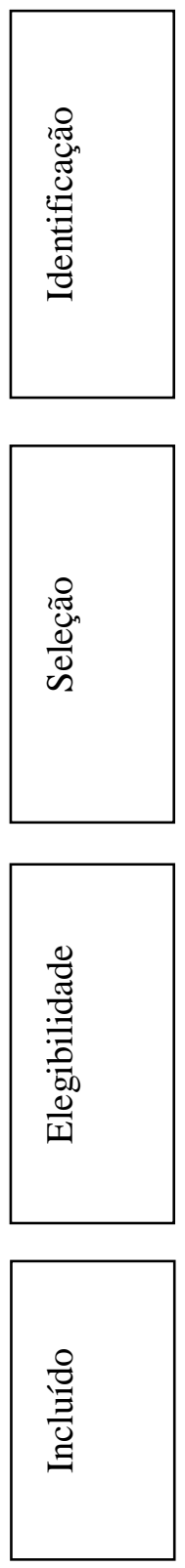

Artigos identificados através da pesquisa de banco de dados

$$
\mathrm{N}^{\circ}=33
$$

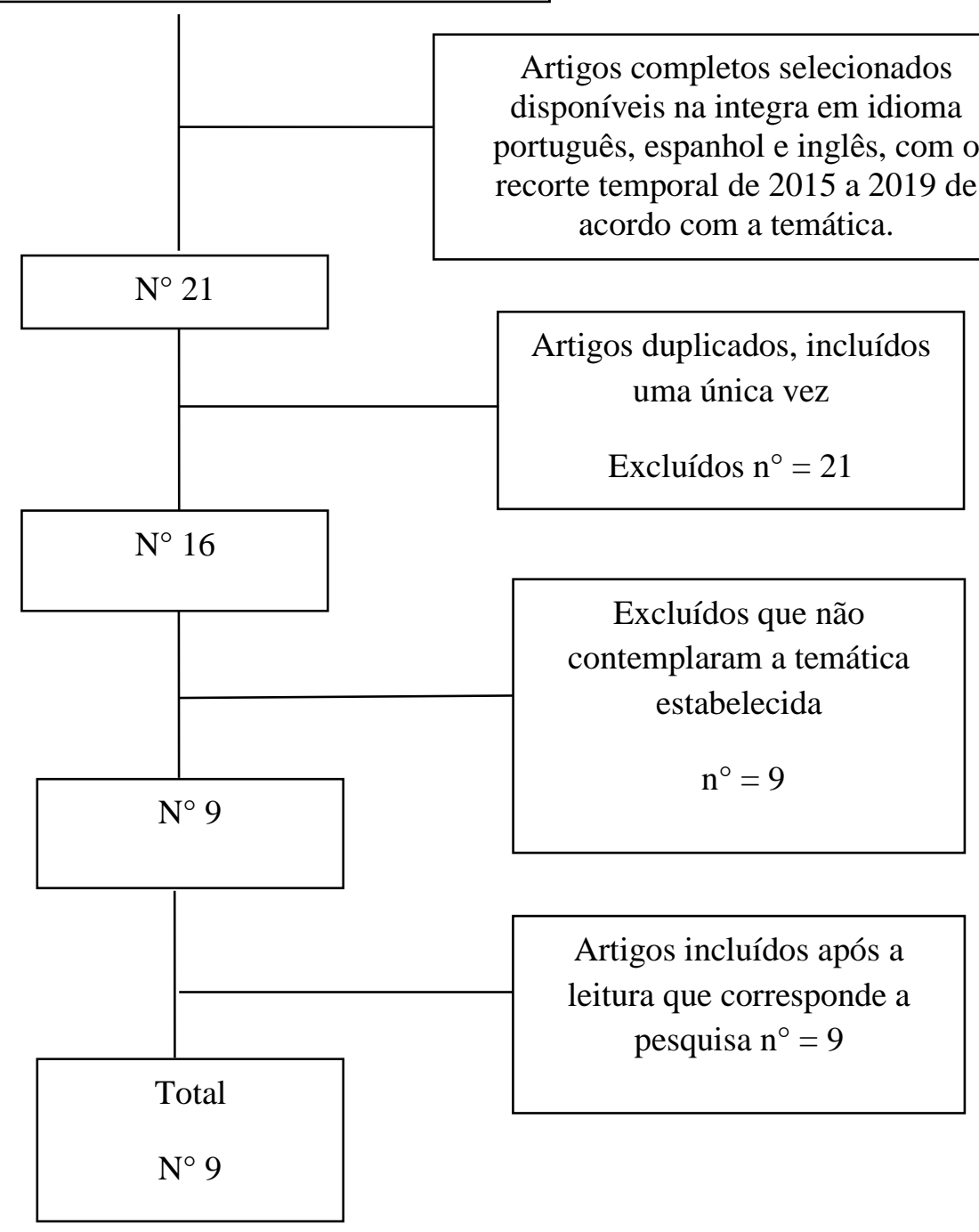

Fonte: Dados pesquisa (2020). 


\section{Resultados e Discussão}

Segundo Pinheiro, Santos Júnior, e Pinheiro (2018), após a PCR os cuidados de enfermagem que devem ser realizados para melhorar o prognóstico do paciente é o uso da hipotermia terapêutica de $32^{\circ} \mathrm{C}$ a $34^{\circ} \mathrm{C}$, considerada como uma confiável temperatura alvo e redução da fração inspirada de oxigênio, com um menor valor para se obter uma saturação arterial de oxigênio de $\geq 94 \%$ e otimização da perfusão cerebral.

De acordo com Beccaria et al., 2017, em uma reanimação considerada satisfatória o enfermeiro em conjunto com o médico deve controlar de forma rigorosa os sinais vitais e os parâmetros hemodinâmicos do paciente, estando atento a qualquer sinal de complicação,bem como a importância do treinamento para garantir um rápido diagnóstico e dar inicio imediato das manobras adequadas, disponibilidade e funcionalidade dos equipamentos do carrinho de parada e o registro de todas as informações no prontuário.

Segundo Morais e Paiva (2017), a RCP de boa qualidade e o uso precoce de um desfibrilador são os principais determinantes na sobrevida com um bom prognóstico neurológico das vítimas após a PCR, e reforça a importância da educação continuada.

Lisboa, Borges, e Monteiro (2016), fala sobre a importância de se avaliar possíveis danos ao pulmão decorrente das manobras de RCP, bem como o uso do capnógrafo para confirmar a posição do tubo e avaliar a profundidade das compressões torácicas. Suporte neurológico nos cuidados pós PCR, prevenção do agravo da lesão cerebral, manutenção com a alimentação por sonda nasoenteral (SNE), os cuidados no aparecimento de lesão por pressão, e esclarecimento a família.

Espíndola, Espíndola, Moura, e Lacerda, 2017, diz que o sucesso do atendimento depende diretamente de uma integração de esforços por parte da equipe, assim como o prévio reconhecimento da parada, iniciando imediatamente a RCP; a desfibrilação e o suporte avançado de vida, englobando recursos como a administração de fármacos, equipamentos especiais de ventilação e cuidados após a PCR, o que vai duplicar ou triplicar a chance de sobrevivência.

De acordo com Sawyer et al. (2020) o processo de recuperação de PCR ocorre por muito tempo ainda depois da hospitalização inicial. É necessário apoio nesta fase com o intuito de garantir bem-estar físico, cognitivo e emocional e o retorno ao funcionamento social e profissional. Recomendam também que as ações devem ser iniciadas já durante a hospitalização inicial e continuar o tempo que for necessário.

Para Moura, Brito, Rocha, e Moura (2019) a utilização das medicações corretas após a reanimação em suas respectivas vias de administração, melhoram o prognóstico do paciente.

Segundo Nascer e Barbieri (2015), após a reanimação e cuidados ofertados pós PCR, as mulheres em idade fértil são mais propensas a sobreviver a alta hospitalar se comparadas aos homens na mesma faixa etária.

Para Taveira (2018), há um déficit de conhecimento teórico e prático por parte da equipe de enfermagem sobre os cuidados pós-PCR, sendo necessária uma constante atualização através da educação continuada, e a utilização da folha de parada para cada paciente com informações da PCR.

Citolino Filho, Santos, Silva, e Nogueira (2015), diz que uma equipe bem treinada, com harmonia e liderança é fundamental para que se mantenha a qualidade do atendimento em situações de PCR, assim como a imediata disposição dos materiais e equipamentos essenciais, assegurando uma assistência segura e eficaz.

Diante dos resultados dessa pesquisa foi criado um quadro com as características principais dos cuidados dos profissionais de enfermagem com as seguintes questões: O que fazer? Quem deve fazer? Justificativa? Com a finalidade do reconhecimento na atuação das suas funções.

Um dos cuidados prioritários aos pacientes após a PCR, é realizar a hipotermia terapêutica. Os estudos voltados para essa prática começaram na década de 1980 e 1990 com dificuldades e limitações no controle da temperatura, deste modo, surgiram mudanças com dispositivos e cuidados seguros para o controle da temperatura (Bernoche et al., 2019). 
De acordo com a Atualização da Diretriz da Ressuscitação Cardiopulmonar e Cuidados Cardiovasculares de Emergência da Sociedade Brasileira de Cardiologia em 2019, há contraindicações para a prática desse cuidado que atualmente é chamado de "Modulação Terapêutica da temperatura", como pacientes com infecções sistêmicas graves e coagulopatia preexistente (Bernoche et al., 2019).

Observa-se no Quadro 1 a apresentação dos artigos utilizados na pesquisa, levando-se em consideração o título, revista, ano de publicação, tipo de pesquisa e país. Observa-se que as publicações encontram-se no período compreendido entre os anos de 2015 a 2019.

Quadro 1. Distribuição dos artigos pelo cruzamento dos descritores da base de dados.

\begin{tabular}{|c|c|c|c|c|c|}
\hline $\mathbf{N}^{\circ}$ & TÍTULO & REVISTA & $\begin{array}{l}\text { ANO DE } \\
\text { PUBLICAÇÃO }\end{array}$ & TIPO DE PESQUISA & PAÍS \\
\hline 1 & $\begin{array}{l}\text { Sobrevivência a parada } \\
\text { cardiorrespiratória intra-hospitalar: } \\
\text { revisão integrativa da literatura }\end{array}$ & $\begin{array}{l}\text { Rev. eletrônica } \\
\text { enferm }\end{array}$ & 2015 & Quantitativo & Brasil \\
\hline 2 & $\begin{array}{c}\text { Fatores que comprometem a qualidade da } \\
\text { ressuscitação cardiopulmonar em } \\
\text { unidades de internação: percepção do } \\
\text { enfermeiro }\end{array}$ & $\begin{array}{l}\text { Rev. Esc. Enferm. } \\
\text { USP }\end{array}$ & 2015 & Quantitativo & Brasil \\
\hline 3 & $\begin{array}{l}\text { Avaliação do conhecimento dos } \\
\text { enfermeiros sobre os cuidados pós- } \\
\text { parada cardiorrespiratória }\end{array}$ & $\begin{array}{l}\text { Rev. enf. UFPE } \\
\text { online }\end{array}$ & 2016 & Quantitativo & Brasil \\
\hline 4 & $\begin{array}{c}\text { Enfermeiros da Atenção Primária em } \\
\text { suporte básico de vida }\end{array}$ & $\begin{array}{l}\text { Rev. ciênc. méd. } \\
\text { (Campinas) }\end{array}$ & 2017 & Quantitativo & Brasil \\
\hline 5 & $\begin{array}{c}\text { Parada cardiorrespiratória: conhecimento } \\
\text { dos profissionais de enfermagem em uma } \\
\text { unidade de terapia intensiva }\end{array}$ & Rev. enf. UFPE onine & 2017 & Quantitativo & Brasil \\
\hline 6 & $\begin{array}{l}\text { Conhecimento teórico da enfermagem } \\
\text { sobre parada cardiorrespiratória e } \\
\text { reanimação cardiocerebral em unidade de } \\
\text { terapia intensiva }\end{array}$ & Cuid. Arte, Enferm & 2017 & Quantitativo & Brasil \\
\hline 7 & $\begin{array}{l}\text { Parada cardiorrespiratória: vigilância, } \\
\text { prevenção e cuidados após a PCR }\end{array}$ & $\begin{array}{l}\text { Rev. pesqui. cuid. } \\
\text { fund (online) }\end{array}$ & 2018 & Quantitativo & Brasil \\
\hline 8 & $\begin{array}{c}\text { Atuação do enfermeiro na equipe de } \\
\text { saúde durante PCR em unidade de terapia } \\
\text { intensiva pediátrica: proposta de } \\
\text { protocolo }\end{array}$ & $\begin{array}{l}\text { MPEA-Teses e } \\
\text { Dissertações }\end{array}$ & 2018 & Quantitativo & Brasil \\
\hline 9 & $\begin{array}{l}\text { Conhecimento e atuação da equipe de } \\
\text { enfermagem de um setor de urgência no } \\
\text { evento parada cardiorrespiratória }\end{array}$ & $\begin{array}{l}\text { Rev. pesqui. cuid. } \\
\text { fund (Online) }\end{array}$ & 2019 & Quantitativo & Brasil \\
\hline
\end{tabular}

Fonte: Dados pesquisa (2020).

O Quadro 2 apresenta as características principais dos cuidados da equipe de enfermagem a serem realizados pós parada cardiorrespiratória. Dividiu-se os achados em "o que fazer", "quem fazer” e suas respectivas justificativas, conforme evidenciado abaixo. 
Quadro 2. Características dos principais cuidados dos profissionais de enfermagem.

\begin{tabular}{|c|c|c|}
\hline O QUE FAZER & QUEM DEVE FAZER & JUSTIFICATIVA \\
\hline Hipotermia terapêutica $32^{\circ} \mathrm{C}$ a $34^{\circ} \mathrm{C}$ & Enfermeiro/Técnico & $\begin{array}{c}\text { Deve ser feita em pacientes adultos, sem resposta sensata a } \\
\text { comandos verbais com RCE após a PCR, constantemente pelo } \\
\text { menos por } 24 \mathrm{~h} \text {. Afim de reduzir a demanda de oxigênio, } \\
\text { promovendo proteção contra isquemia. }\end{array}$ \\
\hline Otimização da perfusão cerebral & Enfermeiro & Evitar progressão de lesões neurológicas. \\
\hline Avaliar saturação de oxigênio $\geq 94 \%$ & Enfermeiro & $\begin{array}{l}\text { Alguns pacientes podem apresentar saturação menor que } 94 \% \text {, } \\
\text { nesses casos deve-se iniciar um suporte de oxigênio. }\end{array}$ \\
\hline Avaliar ritmo cardíaco no monitor & Enfermeiro & Analisar alterações cardíacas. \\
\hline Registrar informações no prontuário & Enfermeiro & $\begin{array}{l}\text { Fornecer informações sobre a assistência prestada, assegurando a } \\
\text { comunicação da equipe e continuidade das informações. }\end{array}$ \\
\hline $\begin{array}{l}\text { Orientação e acolhimento dos } \\
\text { familiares }\end{array}$ & Enfermeiro & $\begin{array}{l}\text { A família deve ser esclarecida sobre todos os procedimentos } \\
\text { prestados. }\end{array}$ \\
\hline $\begin{array}{l}\text { Controle rigoroso dos sinais vitais e } \\
\text { dos parâmetros hemodinâmicos }\end{array}$ & Enfermeiro/Técnico & $\begin{array}{l}\text { O reconhecimento imediato de qualquer alteração, irá refletir no } \\
\text { prognóstico. }\end{array}$ \\
\hline Avaliar função neurológica & Enfermeiro & $\begin{array}{c}\text { Prevenção do agravo da lesão cerebral, aplicando o uso da escala } \\
\text { de coma de glasgow }\end{array}$ \\
\hline Avaliar distúrbio metabólico & Enfermeiro & Prevenção de agravos. \\
\hline $\begin{array}{l}\text { Avaliar danos ao pulmão decorrente } \\
\text { das manobras }\end{array}$ & Enfermeiro & Realizar ausculta pulmonar. \\
\hline $\begin{array}{l}\text { Realizar Briefing com a equipe } \\
\text { presente, salientando os pontos } \\
\text { positivos e os que precisam melhorar }\end{array}$ & Enfermeiro & Melhorar a assistência prestada. \\
\hline Administração de medicamentos & Enfermeiro/Técnico & $\begin{array}{l}\text { Administrar medicações prescritas pelo médico para auxiliar no } \\
\text { tratamento. }\end{array}$ \\
\hline Realizar ECG de 12 derivações & Enfermeiro & Identificar evidências no traçado. \\
\hline $\begin{array}{l}\text { Organização das medicações no } \\
\text { carrinho de parada }\end{array}$ & Enfermeiro & $\begin{array}{c}\text { Após a PCR deve-se realizar a organização dos medicamentos, } \\
\text { repondo o que foi utilizado. }\end{array}$ \\
\hline Mudança de decúbito & Enfermeiro/Técnico & $\begin{array}{c}\text { Realizar mudança a cada } 2 \text { horas, Visando evitar o aparecimento } \\
\text { de lesão por pressão. }\end{array}$ \\
\hline Aspiração de secreções & Enfermeiro & Realizar aspiração sempre que necessário. \\
\hline Tomografia computadorizada & Enfermeiro & $\begin{array}{l}\text { Avaliação do tamanho ventricular, morfologia, função, estado } \\
\text { das valvas cardíacas e circulação. }\end{array}$ \\
\hline Angiografia & Enfermeiro & Para pacientes com suspeita de lesão cardiovascular. \\
\hline Reposição de fluidos & Enfermeiro/técnico & Solução cristalóide $30-40$ ml/Kg/dia IV. \\
\hline Acompanhar o capnógrafo & Enfermeiro & Avaliar correta posição do tubo orotraqueal. \\
\hline
\end{tabular}

Fonte: Adaptado de (Pinheiro et al., 2018; Citolino Filho et al., 2015; Beccaria et al., 2017; Morais e Paiva, 2017; Lisboa et al., 2016; Espíndola et al., 2017; Taveira, 2018; Nascer e Barbieri, 2015; Moura et al., 2019).

Observa-se no Quadro 2 que a equipe de enfermagem exerce atuação direta ao paciente pós parada cardiorrespiratória. Essas atuações vão desde a monitorização hemodinâmica até cuidados como aspiração de vias aéreas e reposição de fluidos. Cabendo a equipe a atuação em conjunto, tendo em vista o respaldo legal que a categoria lhe confere.

\section{Conclusão}

O conteúdo abordado ao longo do presente trabalho demonstra a importância dos cuidados de enfermagem ao paciente após a PCR, bem como sua contribuição direta para a ampliação de conhecimento na área da saúde, visto que os mesmos podem impactar diretamente na sobrevida do paciente. 
Como principais resultados dessa pesquisa, resulta-se que, é atribuição da enfermagem controlar o mecanismo de ação da hipotermia terapêutica, realizar ECG de 12ou 15 derivações, angiografia coronariana, tomografia computadorizada, controle rigoroso dos sinais vitais e dos parâmetros hemodinâmicos, otimização da perfusão cerebral, reposição de fluidos e registro das informações no prontuário.

As investigações apresentadas neste trabalho contribuem de forma significativa para o campo de estudo da urgência e emergência. A criação do quadro informativo configura-se como fonte de consulta que irá nortear os cuidados de enfermagem ao paciente pós parada cadiorrespiratória.

As informações demonstram que muitas outras pesquisas ainda podem ser realizadas sobre cuidados de enfermagem ao paciente pós-PCR, devido à importância do tema e inúmeras contribuições, não só para os profissionais como para o meio acadêmico, com a finalidade de agregar e aprofundar o conhecimento frente à temática.

\section{Referências}

Alves, A. R., Chaves, E. M. C., Freitas, M. C., \& Monteiro, A. R. M. (2007). Aplicação do Processo de Enfermagem: estudo de caso com uma puérpera. Revista Brasileira de Enfermagem, 60(3), 344-347. 10.1590/S0034-71672007000300019

American Heart Association (2015). Destaques da American Heart Association 2015. Atualização das diretrizes de RCP e ACE. Texas, EUA. http://www.bombeiros.ms.gov.br/wp-content/uploads/2015/10/Atualiza\%C3\%A7\%C3\%A3o-das-Diretrizes-de-RCP-e-ACE-2015.pdf

American Heart Association (2020). Atualização das diretrizes de RCP e ACE de 2020 da American Heart Association. https://eccguidelines.heart.org/wpcontent/uploads/2015/10/2015-AHA-Guidelines-Highlights-Portuguese.pdf

Beccaria, L. M., Santos, K. F., Trombeta, J. C., Rodrigues, A. M. S., Barbosa, T. P., \& Jacon, J. C. (2017). Conhecimento teórico da enfermagem sobre parada cardiorrespiratória e reanimação cardiocerebral em unidade de terapia intensiva. CuidArte. Enfermagem, 11(1): 51-58. http://www.webfipa.net/facfipa/ner/sumarios/cuidarte/2017v1/7\%20Artigo\%20Conhecimento\%20Enfermagem\%20Parada\%20cardiorrespirat\%C3\%B3ria\%20 PCR.pdf

Bernoche, C., Timerman, S., Polastri, T. F., Giannetti, N. S., Siqueira, A. W. S., Piscopo, A., \& Sako, Y. K. (2019). Atualização da diretriz de ressuscitação cardiopulmonar e cuidados cardiovasculares de emergência da Sociedade Brasileira de Cardiologia - 2019. Arquivos Brasileiros de Cardiologia, 113(3), 449663. 10.5935/abc. 20190203

Carvalho, A. S. A., Santos, F. F., \& Viana, E. R. (2015). Atuação e liderança do enfermeiro frente à parada cardiorrespiratória na unidade de terapia intensiva. Biológicas \& Saúde, 18(5), 30-31. 10.25242/88685182015765

Castanheira, J. S., Oliveira, S. G., Rocha, L. P., Neutzling, B. R. S., Cadaval, P. P. M., \& Leite, S.S. (2020). Assistência na parada cardiorrespiratória: estruturas do cuidado em saúde em uma unidade de internação hospitalar. Research, Society and Development, 9(9), e329997319. 10.33448/rsd-v9i9.7319

Citolino Filho, C. M., Santos, E. S., Silva, R. C. G., \& Nogueira, L. S. (2015). Factors affecting the quality of cardiopulmonary resuscitation in inpatient units: perception of nurses. Revista da Escola de Enfermagem da USP, 49(6), 907-913. 10.1590/S0080-623420150000600005

Costa, T. P., Santos, C. P., \& Silva, R. F. A. (2014). Correlação entre o algoritmo de cuidados pós-parada cardiorrespiratória e a classificação das intervenções de enfermagem (NIC). Revista de Pesquisa: Cuidado é Fundamental Online, 6(1), 241-248. 10.9789/2175-5361.2014v6n1p241

Cruz, L. L. D., Rêgo, M. G., \& Lima, C. V. (2019). O enfermeiro frente à parada cardiorrespiratória em ambiente hospitalar: desafios do cotidiano. Refaci. https://dspace.uniceplac.edu.br/bitstream/123456789/82/1/Lidiane\%20Cruz_0000748_Marina\%20R\%C3\%AAgo_0000089.pdf.

Espíndola, M. C. M., Espíndola, M. M. M., Moura, L. T. R., \& Lacerda, L. C. A. (2017). Parada cardiorrespiratória: conhecimento dos profissionais de enfermagem em uma unidade de terapia intensiva. Revista de enfermagem UFPE on line, 11(7): 2773-2778. 10.5205/reuol.10939-97553-1-RV.1107201717

Lisboa, N. S., Borges, M. S., \& Monteiro, P.S. (2016). Assessment of the knowledge of nurses on post-cardiopulmonary arrest care. Revista de enfermagem UFPE on line, 10(10): 3778-3786. 10.5205/reuol.9667-87805-1-ED1010201608

Mendes, K. D. S., Silveira, R. C. C. P., \& Galvão, C. M. (2008). Revisão integrativa: método de pesquisa para a incorporação de evidências na saúde e na enfermagem. Texto \& contexto enfermagem, 17(4), 758-764. 10.1590/S0104-07072008000400018

Moura, J. G., Brito, M. P. S., Rocha, G. O. S., \& de Moura, L. T. R. (2019). The knowledge and acting of a nursing team from a sector of cardiorespiratory arrest urgent care. Revista de Pesquisa: Cuidado é Fundamental Online, 11(3): 634-640. 10.9789/2175-5361.2019.v11i3.634-640

Moraes, T. P. R., \& Paiva, E. F. (2017). Enfermeiros da Atenção Primária em suporte básico de vida. Revista de Ciências Médicas, 26(1): 9. 10.24220/2318$0897 \mathrm{v} 26 \mathrm{n} 1 \mathrm{a} 3783$

Nascer, D. T., \& Barbieri, A. R. (2015). Survival of in-hospital cardiorrespiratory arrest: integrative review of the literature. Revista Eletrônica de Enfermagem, 17(3). 10.5216/ree.v17i3.30792

Pinheiro, D. B. S., Santos Júnior, E. B., \& Pinheiro, L. S. B. (2018). Cardiorespiratory arrest: surveillance, prevention and care after PCR. Revista de Pesquisa: Cuidado é Fundamental Online, 10(2), 577-584. 10.9789/2175-5361.2018.v10i2.577-584 
Research, Society and Development, v. 10, n. 4, e9310413861, 2021

(CC BY 4.0) | ISSN 2525-3409 | DOI: http://dx.doi.org/10.33448/rsd-v10i4.13861

Sawyer, K. N., Camp-Rogers, T. R., Kotini-Shah, P., Rios, M., Gossip, M. R., Moitra, V. K., \& Kurz, M. C. (2020). Sudden cardiac arrest survivorship: a scientific statement from the American Heart Association. Circulation, 141(12): e654-e685. 10.1161/CIR.0000000000000747

Taveira, R. P. C. (2018). Atuação do enfermeiro na equipe de saúde durante parada cardiorrespiratória em Unidade de Terapia Intensiva Pediátrica: proposta de protocolo. Dissertação (Mestrado em Enfermagem). Escola de Enfermagem Aurora de Afonso Costa, Universidade Federal Fluminense, Brasil. 